\title{
Volumetric and Viscometric Studies of Copper Surfactant Derived from Karanj (Pongamia pinnata) Oil in Methanol-benzene Mixture at 298.15 K
}

\author{
Shema Khan, ${ }^{1}$ Rashmi Sharma ${ }^{2}$ and Arun Kumar Sharma ${ }^{3 *}$ \\ ${ }^{1}$ Department of Chemistry, S. R. K. P. Govt. P. G. College, \\ Kishngarh-305801, Rajasthan, India \\ ${ }^{2}$ Department of Chemistry, Smrat Prathviraj Chauhan Government College, \\ Ajmer-305001, Rajasthan, India \\ ${ }^{3}$ Department of Chemistry, Government Post Graduate College, \\ Jhalawar-326001, Rajasthan, India \\ *Corresponding author: sharmaarun423@gmail.com
}

Published online: 25 August 2019

To cite this article: Khan, S., Sharma, R. \& Sharma, A. K. (2019). Volumetric and viscometric studies of copper surfactant derived from karanj (Pongamia pinnata) oil in methanol-benzene mixture at 298.15 K. J. Phys. Sci., 30(2), 51-68, https://doi.org/10.21315/jps2019.30.2.4

To link to this article: https://doi.org/10.21315/jps2019.30.2.4

\begin{abstract}
The density, molar volume, apparent molar volume, viscosity and other parameters of $\mathrm{Cu}(\mathrm{II})$ surfactant derived from karanj oil in non-aqueous solvents of varying compositions have been determined at constant temperature $298.15 \mathrm{~K}$. The results were used to determine the critical micelle concentration (CMC), soap-solvent interactions and the effect of chain length of the surface active molecule on various parameters. The CMC values of copper karanj soap solutions decreased with the increase in the concentration of polar solvent methanol in the solvent mixture. These studies were done to study the solution behaviour, micellar features and various interactions of the derived biologically active surfactant with polar and non-polar solvents to understand the applied part of the molecule. The apparent molar volume has been examined in terms of Masson equation, and the limiting apparent molar volume has been interpreted in terms of solute-solvent interaction. The detailed study of aforesaid compounds clearly indicates that the solutesolvent interaction decreases with the increase in ring strain and size of the synthesised complexes. The conclusions with regard to solute-solute and solute-solvent interaction have been discussed in terms of well-known Moulik's and Jones-Dole equations. This vital information plays an important role in the selection of the synthesised molecule for various industrial and biological applications.
\end{abstract}

Keywords: $\mathrm{Cu}$ (II) soap, non-edible oils, soap-solvent interaction, CMC, viscosity 


\section{INTRODUCTION}

$\mathrm{Cu}$ (II) surfactants have found various applications in many industrial uses and play an important role in the colloid chemical phenomena. The exact information on the nature and structure of these compounds are of great significance in explaining their characteristics under different conditions. Recently, work on polymetallic complexes and transition metal complexes of heterocyclic ligands has been done, and their structure and biological characteristics have also been discussed. ${ }^{1,2}$ Additionally, researchers studied the molar volume and other parameters of various soaps. ${ }^{3,4}$ Many nitrogen and sulphur containing compounds were synthesised and investigated for a wide range of pharmacological and biological activities. ${ }^{5}$ They have been used as tranquilisers, sedatives, anti-inflammatory agents, antiviral, anti-malarial fungicide, bactericide, etc. ${ }^{6}$ As apparent molar volume of a solute reflects the cumulative effects of solute-solute and solute-solvent interactions, such data are expected to highlight the role of the cation and anion of a weak electrolyte in influencing its apparent molar volumes at infinite dilution on mixed solvent systems. ${ }^{7,8}$ The present work deals with the study of density, viscosity and other parameters derived from various equations of copper soap synthesised from (Pongamia pinnata) or karanj oil in a ternary system. The effect of soap concentration on viscosity of the solution in polar and non-polar solvent has been discussed in terms of Jones-Dole equations. ${ }^{9}$

The density parameters are important to understand the colloidal behaviour, critical micelle concentration (CMC) characteristics and nature of the complexes. These studies indirectly help in identifying the structural insight, physical and biochemical properties of these class heterocyclic complexes. ${ }^{10-12}$ The studies will definitely help future researchers to apply these novel binuclear complexes in multiple interlinked fields based on their widest applicability. ${ }^{13,14}$ Overall, the present course of study helps us to understand the characteristic nature and application of biological active metal soaps. ${ }^{15}$ The study definitely generates a new hope in biological, pharmacological and therapeutic testing. ${ }^{16}$ It is anticipated that it will generate a new hope in various industrial and analytical applications. ${ }^{17}$ This information is of fundamental importance for understanding solute-solute, solvent-solvent interactions in solutions below and above CMS. ${ }^{18}$

\section{EXPERIMENTAL}

All the chemicals used were of LR/AR grade. Copper soap was prepared by refluxing the non-edible oil, i.e., karanj oil (extracted from kernels and purified) with ethyl alcohol and 2N KOH solutions for 3-4 h (Direct Metathesis). ${ }^{19}$ The neutralisation of excess $\mathrm{KOH}$ present was done by slow addition of $0.5 \mathrm{~N} \mathrm{HCl}{ }^{20}$ 
Saturated solution of copper sulphate was then added to it to convert neutralised potassium soap into their corresponding copper soap. Copper soap obtained was then washed with warm water and $10 \%$ alcohol at $50^{\circ} \mathrm{C}$ and recrystallised using hot benzene. Molecular weights of copper soaps were determined from saponification value. ${ }^{21}$ The copper soap is abbreviated as copper-karanj (CK). The physical and analytical data given in Table 1.

Table 1: Analytical and physical data of CK soap.

\begin{tabular}{lcccccccc}
\hline \multirow{2}{*}{$\begin{array}{l}\text { Name of } \\
\text { soap }\end{array}$} & Colour & M.P. $\left({ }^{\circ} \mathrm{C}\right)$ & \multicolumn{2}{c}{ Metal content } & \multirow{2}{*}{ S.V. } & S.E. & Av. Mol.wt. \\
\cline { 4 - 5 } CK & $\begin{array}{l}\text { Dark } \\
\text { green }\end{array}$ & 51 & 9.4996 & 9.3426 & 181.5 & 309.091 & 679.682 \\
\hline
\end{tabular}

\subsection{Characterisation of CK Soap}

In order to study the structure of soap, the infrared absorption spectra of compound was obtained on a Fourier transform infrared (FTIR) spectrophotometer, Shimadzu 821PC (4000-400 $\left.\mathrm{cm}^{-1}\right)$ from analytical instrument facility, CDRI, Lucknow, India. Proton NMR spectra were also recorded at SAIF, CDRI, Lucknow, on NMR spectrometers, Bruker DRX-300 at $300 \mathrm{~K}$ using $\mathrm{C}_{6} \mathrm{D}_{6}$ (deuterated benzene) as solvent for soap.

\subsubsection{IR spectral analysis}

The absorption bands observed at $2927.6 \mathrm{~cm}^{-1}$ and $2855.7 \mathrm{~cm}^{-1}$ correspond to asymmetric and symmetric stretching of methylene $\left(-\mathrm{CH}_{2}\right)$ group in the IR spectra investigation of pure copper karanj soap, with the overlapping of $\mathrm{CH}_{3}$ anti-symmetrical C-H $\left(v_{a s}\right)$ at $2962 \mathrm{~cm}^{-1}$ and symmetrical C-H $\left(v_{s}\right)$ stretching at $2872 \mathrm{~cm}^{-1}$, respectively. The presence of absorption band at $3018.4 \mathrm{~cm}^{-1}$ corresponds to olefinic $=\mathrm{C}-\mathrm{H}$ stretch and the un-conjugated $\mathrm{C}=\mathrm{C}$ stretching peaks are very much distinguished at $1655.8 \mathrm{~cm}^{-1}$ with two medium bands at $3018.4 \mathrm{~cm}^{-1}$ and $1655.8 \mathrm{~cm}^{-1}$, and a strong band at $759.1 \mathrm{~cm}^{-1}$ confirms the cisnature of alkenes. This out of plane $\mathrm{C}-\mathrm{H}$ bending vibration of alkene is the most characteristic vibrational mode of alkene. ${ }^{22}$ It is clear from the spectra of CK soap that it usually is the strongest in the spectra of alkenes. The absorption peak at $1419.2 \mathrm{~cm}^{-1}$ is representative of symmetric C-H deformation bands of $=\mathrm{C}-\mathrm{H}$ group.

The absorption band near $1377.3 \mathrm{~cm}^{-1}$ is very stable in position arising from the symmetric bending of the methyl $\mathrm{C}-\mathrm{H}$ showing that the methyl group is attached to another carbon atom. The in-plane bending $\left(\delta_{\mathrm{s}}\right)$ scissoring band of $\mathrm{C}-\mathrm{H}$ of methylene group is positioned at $1462.8 \mathrm{~cm}^{-1}$. This peak may also be assigned to 
$\mathrm{C}-\mathrm{H}$ asymmetrical bending vibration of methyl group as it generally overlaps the scissoring vibrations of methylene group.

The peaks $1609.3 \mathrm{~cm}^{-1}$ and $1216.2 \mathrm{~cm}^{-1}$ may be assigned to carboxylate ion $\mathrm{COO}^{-}, \mathrm{C}-\mathrm{O}$ anti-symmetric and symmetric stretching, respectively. Also, a very clear $>\mathrm{C}=\mathrm{O}$ stretching is also observed at $1736 \mathrm{~cm}^{-1}$, while a small peak at $1345 \mathrm{~cm}^{-1}$ corresponds to $\mathrm{CH}_{2}$ twisting and wagging and $669.2 \mathrm{~cm}^{-1}$ to $\mathrm{C}-\mathrm{H}$ rocking. ${ }^{23}$ Copper-oxygen $(\mathrm{Cu}-\mathrm{O})$ stretching bands have been distinguished at $480 \mathrm{~cm}^{-1}$ (Table2).

Table 2: IR spectral data for CK soap.

\begin{tabular}{|c|c|}
\hline Absorption bands & $\mathrm{CK}\left(\mathrm{cm}^{-1}\right)$ \\
\hline Olefinic $=\mathrm{C}-\mathrm{H}$ stretching & 3018.4 \\
\hline $\begin{array}{l}-\mathrm{CH}_{3} \text { and }-\mathrm{CH}_{2},-\mathrm{C}-\mathrm{H} \\
\text { antisymmetric stretching }\left(\mathrm{d}_{\mathrm{as}}\right)\end{array}$ & 2927.6 \\
\hline $\begin{array}{l}-\mathrm{CH}_{3} \text { and }-\mathrm{CH}_{2},-\mathrm{C}-\mathrm{H} \\
\text { symmetric stretching }\left(\mathrm{d}_{\mathrm{s}}\right)\end{array}$ & 2855.7 \\
\hline$>\mathrm{C}=\mathrm{O}$ stretching & 1736.0 \\
\hline$-\mathrm{C}=\mathrm{C}$ stretching (cis unconjugated) & 1655.8 \\
\hline -COO-, -C-O antisymmetric stretching & 1609.3 \\
\hline $\begin{array}{l}-\mathrm{CH}_{2},-\mathrm{C}-\mathrm{H} \text { in plane bending }\left(\mathrm{d}_{\mathrm{s}}\right) \text { (scissoring) and asymmetric } \\
\text { vibration of }-\mathrm{C}-\mathrm{H}\left(-\mathrm{CH}_{3}\right) \text { overlapping the former }\end{array}$ & 1462.8 and $\sim 1445$ \\
\hline$-\mathrm{C}-\mathrm{H}$ def. $=\mathrm{C}-\mathrm{H}$ (rocking) & 1419.2 \\
\hline $\begin{array}{l}-\mathrm{CH}_{3},-\mathrm{C}-\mathrm{H} \\
\text { symmetric bending }\left(\mathrm{d}_{\mathrm{s}}\right)\end{array}$ & 1377.3 \\
\hline$-\mathrm{CH}_{2},-\mathrm{C}-\mathrm{H}$ bending ( $\delta$ twisting and wagging) & 1345 \\
\hline $\begin{array}{l}-\mathrm{COO}- \\
-\mathrm{CC}(=\mathrm{O})-\mathrm{O} \text { symmetric stretching }\end{array}$ & 1216.2 \\
\hline $\begin{array}{l}=\mathrm{C}-\mathrm{H}, \text { out of plane bending of } \\
-\mathrm{C}-\mathrm{H} \text { (strong) }\end{array}$ & 759.1 \\
\hline$-\mathrm{CH}_{2},-\mathrm{C}-\mathrm{H}$ rocking & 669.2 \\
\hline $\mathrm{Cu}-\mathrm{O}$ stretching & 480 \\
\hline
\end{tabular}

\subsubsection{NMR Spectral analysis}

The CK showed signal as a triplet at $0.918 \delta, 0.969 \delta 0.987 \delta$ and $1.290 \delta$ representing the aliphatic $-\mathrm{CH}_{3}$ proton and $\mathrm{CH}_{2}$ proton attached to $-\mathrm{CH}_{2}-\mathrm{R}$ group. ${ }^{24}$ While the peak at $2.093 \delta$ represents the proton of $-\mathrm{CH}_{2}$ group attached to $\mathrm{C}=\mathrm{C}$ group. Vinylic proton gave signal at 5.4748. The peaks at $2.233 \delta$ and $1.590 \delta$ correspond to $\mathrm{CH}_{2}$ proton on $\alpha$ and $\beta$ carbon linked to (-COO) ${ }_{2} \mathrm{Cu}$ group. All the peaks are due to the 
long chain fatty acid content $(\mathrm{R})$ of the soap molecule $\left[(\mathrm{RCOO})_{2} \mathrm{Cu}\right]$, shown in Table 3.

Table 3: NMR spectral data for CK soap.

\begin{tabular}{ll}
\hline Peak/signal & $\mathrm{CK}$ \\
\hline$-\mathrm{CH}_{3}-\mathrm{CH}_{2}-\mathrm{R}$ & 0.918 \\
$-\mathrm{CH}_{2}-\mathrm{CH}_{2}-\mathrm{R}$ & 1.229 \\
& 1.290 \\
$-\mathrm{CH}_{2}-\mathrm{C}=\mathrm{C}-$ & 2.093 \\
& 2.107 \\
$-\mathrm{C}=\mathrm{C}-\mathrm{H}$ & 5.254 \\
(vinylic proton) & 5.474 \\
& 5.489 \\
& 5.507 \\
$-\mathrm{CH}_{2}-\mathrm{C}(=\mathrm{O}) \mathrm{OCu}$ & 5.549 \\
$-\mathrm{CH}_{2}-\mathrm{CH}-\mathrm{C}(=\mathrm{O}) \mathrm{OCu}$ & 2.233 \\
\hline
\end{tabular}

\subsection{Measurement of Density}

Ostwald's modification of Sprengel pycnometer with a volume of about $10 \mathrm{ml}$ was used for measuring the density of the soap solution in the thermo stated bath at $298.15 \mathrm{~K}$. The density of the solutions was calculated by the following relationship. The measured values of density compared with literature values. ${ }^{25}$ The possible error in the density was estimated to be less than. The density $\rho$ was reproducible to within $0 \mathrm{~kg} \mathrm{~m}^{-3}$ :

$$
\rho=\frac{\omega}{\omega_{0}}
$$

where $w$ and $w_{0}$ are the weights (same volume) of solution and water, respectively.

\subsection{Evaluation of Molar Volume}

The molar volume of the complex solution $\mathrm{V}$ has been calculated by the following relationship: ${ }^{26}$

$$
\nabla=\frac{M_{1} X_{1}+M_{2} X_{2}+M_{3} X_{3}}{\rho}
$$

where $X_{1}$ is the mole fraction of the soap of molecular weight $M_{1}$ whereas $X_{2}$ is the mole fraction of benzene of molecular weight $M_{2}$, and $X_{3}$ is the mole fraction of 
methanol of molecular weight $\mathrm{M}_{3}$. On the other hand, $\rho$ stands for density of the solution. The molar volume was reproducible to within $0 \mathrm{~m}^{3} \mathrm{~mol}^{-1}$.

\subsection{Evaluation of Apparent Molar Volume}

The apparent molar volume has been calculated from the density data using the following equation: ${ }^{27}$

$$
\phi_{v}=\frac{M}{\rho^{0}}+\frac{1000\left(\rho_{0}-\rho\right)}{c . \rho^{0}}
$$

where $\rho_{0}$ represents the density of the solvent, $\rho$ is the density of the soap solution, $\mathrm{M}$ is the molecular weight of the soap, and $c$ is the concentration of solution in mol $1^{-1}$. The A.M.V. was reproducible to within $0 \mathrm{~m}^{3} \mathrm{~mol}^{-1}$.

\subsection{Evaluation of Viscosity}

The viscosity of the soap solutions was calculated by the following relationship. ${ }^{28}$

$$
\frac{\eta_{0}}{\eta}=\frac{\rho_{0} \cdot t_{0}}{\rho . t}
$$

where $\eta_{0}, \eta, \rho_{0}, \rho, t_{0}$ and $t$ are the viscosity, density and time of flow for the known and unknown solutions, respectively. The viscosity $\eta$ was reproducible to within $\mathrm{mPa} \mathrm{s}^{-1}$.

\section{RESULTS AND DISCUSSION}

\subsection{Density}

The effect of varying soap concentrations on the density of $\mathrm{Cu}$ (II) karanj soap solution in $100 \%$ benzene, $80 \%$ benzene-methanol and $60 \%$ benzene-methanol in methanol benzene solvent were studied and the solutions were abbreviated as $\mathrm{CK}_{100}, \mathrm{CK}_{80}$ and $\mathrm{CK}_{60}$, respectively. The density of $\mathrm{CK}$ soap solutions initially increases and then decreases and shows a sudden increase again. The plot of density $\rho$ against concentration $c\left(\mathrm{~mol} \mathrm{l}^{-1}\right)$ is characterised by an intersection of two convex curves with reference to $\mathrm{X}$-axis. The point of intersection of possible two straight lines at a definite concentration corresponds to the CMC (Figure 1) suggests the sudden change in density, i.e., behaviour of the solution. ${ }^{29}$ The CMC values of copper karanj soap solutions decreases with the increase in methanol the polar solvent. The CMC of the CK soap solution:

$$
\mathrm{CK}_{100}>\mathrm{CK}_{80}>\mathrm{CK}_{60}
$$


This difference clearly demonstrates that agglomeration of soap molecules initiates at a slightly lower soap concentration with the increase of methanol the polar solvent in benzene. This fact suggests that micellar entities are formed a little more easily and efficiently at a much lower soap concentration in the system with higher percentage of polar solvent. It is known that the CMC decreases by about one third per methylene group in aqueous solutions because the energy required to transfer a methylene group from micelle to bulk in small as intermolecular forces are stronger in polar solvents like water and methanol, whereas in non-polar solvents like benzene, these intermolecular forces are weaker.

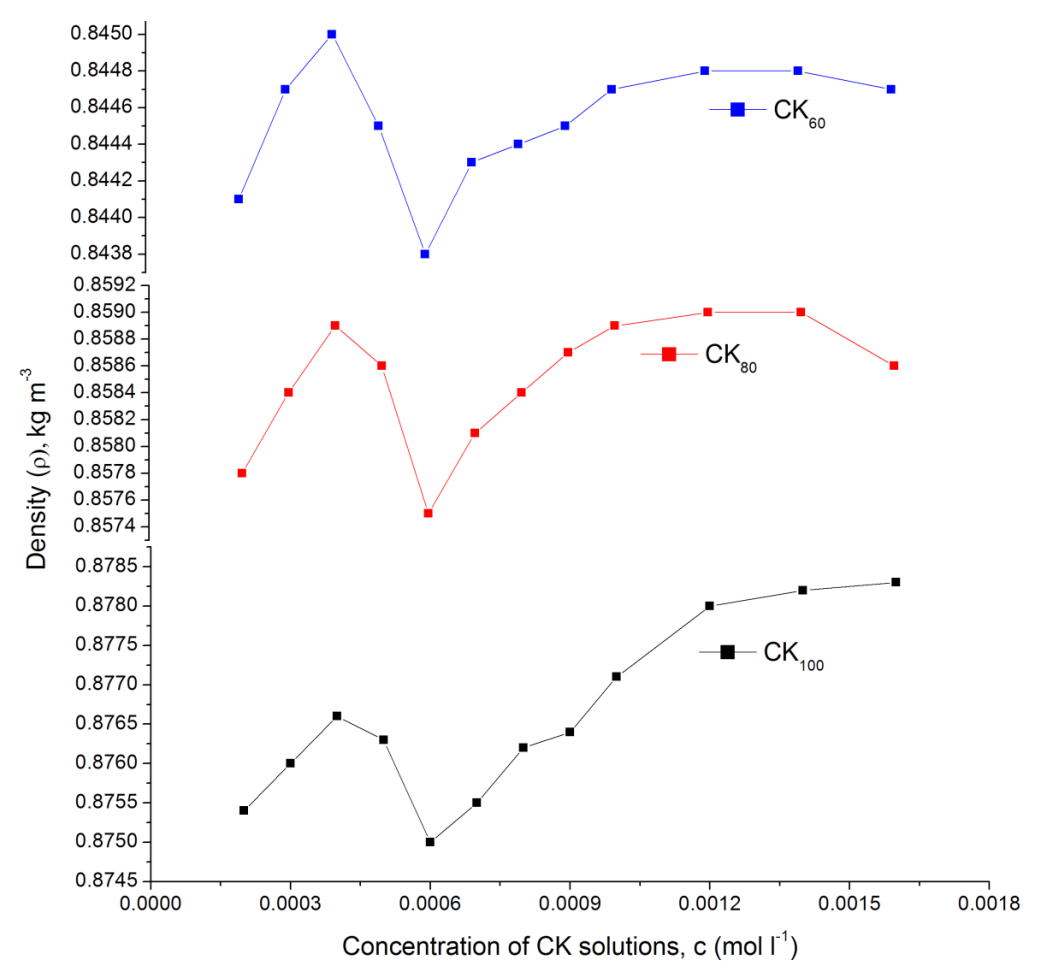

Figure 1: Plot of density versus concentration for $\mathrm{CK}$ soap solutions in $\mathrm{CK}_{100}, \mathrm{CK}_{80}$ and $\mathrm{CK}_{60}$ at $298.15 \mathrm{~K}$.

\subsection{Molar Volume}

The effect of varying soap concentrations on the molar volume of CK soap solution in benzene, $80 \%$ benzene-methanol and $60 \%$ benzene-methanol is observed and mentioned below:

$$
\mathrm{CK}_{100}>\mathrm{CK}_{80}>\mathrm{CK}_{60}
$$


The molar volume of $\mathrm{CK}$ soap solutions also initially decreases and then increases and shows a sudden decrease again. The plot of molar volume $\overline{\mathrm{V}}$ against concentration is characterised by an intersection of two concave curves (Figure 2).



Figure 2: Plot of molar volume versus concentration for $\mathrm{CK}$ soap solutions in $\mathrm{CK}_{100}, \mathrm{CK}_{80}$ and $\mathrm{CK}_{60}$ at $298.15 \mathrm{~K}$.

\subsection{Apparent Molar Volume}

The effect of varying soap concentrations on the apparent molar volume of CK soap solution in $100 \%$ benzene, $80 \%$ benzene-methanol and $60 \%$ benzene-methanol is observed and mentioned herewith:

$$
\mathrm{CK}_{100}>\mathrm{CK}_{80}>\mathrm{CK}_{60}
$$

The plot of molar volume $\overline{\mathrm{V}}$ against concentration is characterised by an intersection of two concave curves, shown in Figure 3. 


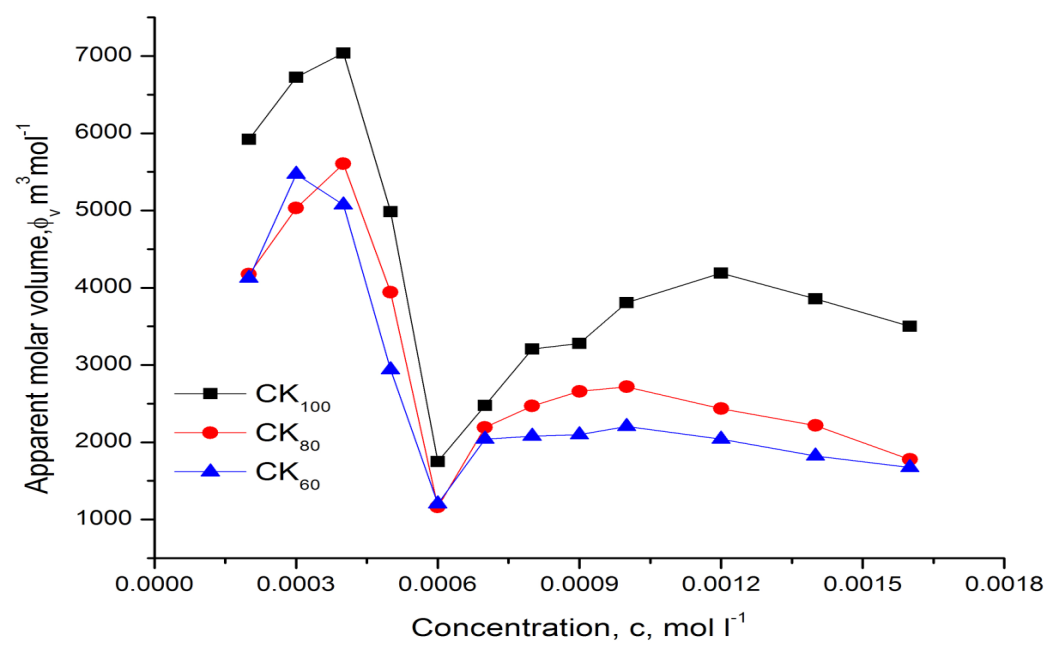

Figure 3: Plot of apparent molar volume versus concentration of CK soap solutions in $\mathrm{CK}_{100}, \mathrm{CK}_{80}$ and $\mathrm{CK}_{60}$ at $298.15 \mathrm{~K}$.

To explore these observations of various researchers in our referred systems the data has been analysed in terms of Masson's equation: ${ }^{31}$

$$
\phi_{v}=\phi_{v}^{0}+\mathrm{S} \sqrt{c}
$$

Here, $\phi_{v}$ represents apparent molar volume, whereas $\phi_{v}^{0}$ and $S_{v}$ represent limiting apparent molar volume and limiting apparent slope, respectively. $\phi_{v}^{0}$ and $S_{v}$ have been regarded as the measure of solute-solvent interactions and solute-solute interactions, respectively.

According to our observation of $\phi_{v}$ volume for CK soap, their some negative volume could be ascribed to the earlier study done on the basis of group additively. ${ }^{16}$ Some trends that are observed can be explained, at least partially, in terms of structural ion-ion interactions, i.e., hydrophilic-hydrophilic, hydrophilic-hydrophobicand and hydrophobic-hydrophobic interactions. The solute which is studied is CK soap with both hydrophilic and hydrophobic features, i.e., $\mathrm{COO}^{-}$of fatty acid chain is hydrophilic in nature and long alkyl chain is hydrophobic in nature. On the other hand, the solvents, i.e., non-polar solvent, benzene is hydrophobic and polar solvent methanol is hydrophilicin nature. Thus, the various interactions occurring between solute and solvent have been analysed. ${ }^{30}$ 
The plot of $\phi_{v}$ against $\sqrt{c}_{c}$ is characterised by an intersection of two convex curves with reference to X-axis (Figure 4). The point of intersection of possible two straight lines in the curves at a definite concentration corresponds to the critical micelle concentration. Of course, this is the maximum concentration of molecular dispersion at which there is balancing of internal forces causing the formation of micelles. The value of apparent molar volume $\phi_{v}$ shows a sharp decrease below $\mathrm{CMC}$ and increases above CMC in CK soap solution in pure benzene, $80 \%$ benzene-methanol and $60 \%$ benzene-methanol system.

The CMC obtained from plot of $\phi_{v}$ against $\sqrt{ }_{c}$ has also been confirmed by the density and molar volume measurements. The CMC obtained in this study, is in good agreement with the physical properties like viscosity and various ultrasonic parameters.

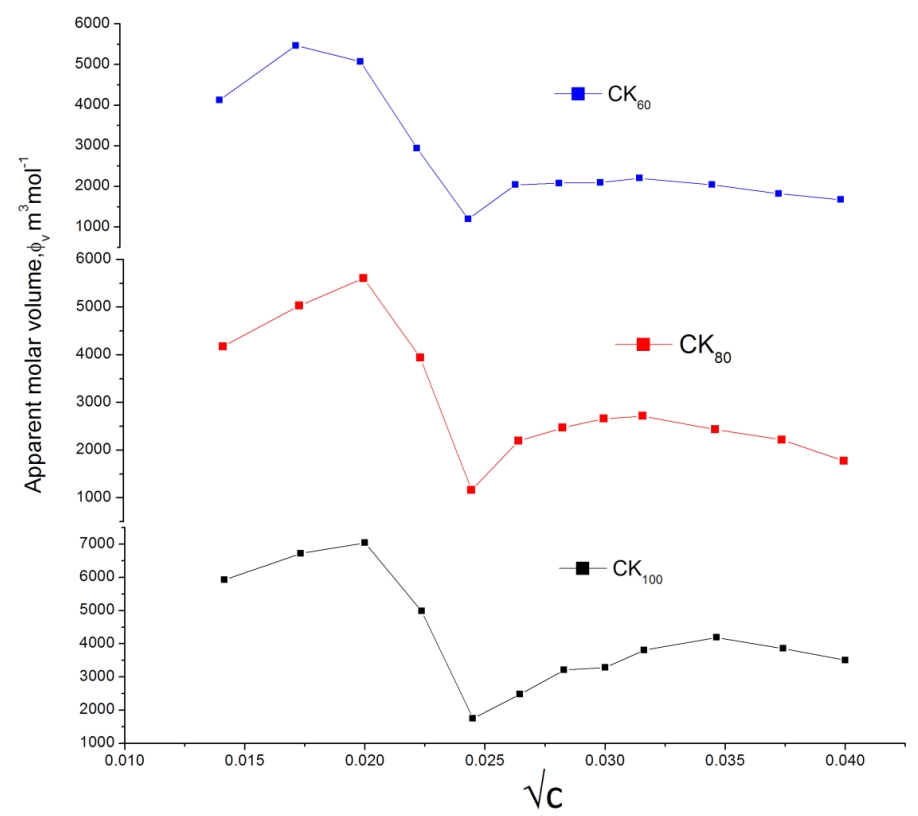

Figure 4: Plot of apparent molar volume versus $\sqrt{ } \mathrm{c}$ of $\mathrm{CK}$ soap solutions in $\mathrm{CK}_{100}, \mathrm{CK}_{80}$ and $\mathrm{CK}_{60}$ at $298.15 \mathrm{~K}$ (Moulik's equation). 
Masson's equation (Equation 5) given earlier fits well both below and above $\mathrm{CMC}$ as the plot is characterised by an intersection of possible two straight lines. The value of limiting apparent molar volume $\left(\phi_{v}^{0}\right)$ for the soap is obtained by the extrapolation of $\phi_{v}$ against $\sqrt{ }_{c}$ plot to $C \rightarrow 0$. Two values of $\phi_{v}^{0}$ are obtained which are referred to as $\phi_{v 1}{ }^{0}$ (below CMC) and $\phi_{v 2}{ }^{0}$ (above CMC) as the Masson's equation is applicable to the two intersecting straight lines.

It is obvious from Table 4 that $\phi_{v 1}{ }^{0}>\phi_{v 2}{ }^{0}$ for CK soap solutions. Thus, for CK soap solute-solvent interaction is more pronounced below CMC as compared to above. This may be ascribed to the favourable interactions between soap-solvent molecules before formation of the micelles.

Table 4: Computed parameters of Masson's equation for CK soap solutions in $\mathrm{CK}_{100}$, $\mathrm{CK}_{80}$ and $\mathrm{CK}_{60}$ at $298.15 \mathrm{~K}$.

\begin{tabular}{lcccc}
\hline Soap solution & $\mathrm{f}_{\mathrm{v} 1}{ }^{\circ}$ & $\mathrm{f}_{\mathrm{v} 2}{ }^{\circ}$ & $\mathrm{S}_{\mathrm{v} 1}$ & $\mathrm{~S}_{\mathrm{v} 2}$ \\
\hline $\mathrm{CK}_{100}$ & 30692.70 & -7680.71 & -1171254.33 & 384608.81 \\
$\mathrm{CK}_{80}$ & 25483.56 & -1286.09 & -983334.15 & 131929.94 \\
$\mathrm{CK}_{60}$ & 22287.34 & +1182.15 & -862279.80 & 32192.21 \\
\hline
\end{tabular}

Similarly, the parameter $S_{v}$ in Masson's equation represents the limiting apparent slope and is indicative of solute-solute interactions. A greater magnitude of $S_{v}$ shall be referred to as greater solute-solute (i.e., soap-soap) interactions. It is reasonable to determine two values of parameters $S_{v}$, i.e., below and above CMC designated as $S_{v 1}$ and $S_{v 2}$, respectively. It is evident from Table 4 that values of $S_{v}$ parameters follow the order $S_{v 1}<S_{v 2}$. Therefore, it can be concluded that solutesolute interactions become more pronounced above CMC with respect to solvents the observed order for $\phi_{v 2}{ }^{0}$ and $S_{v 2}$, i.e., above CMC:

$$
\begin{array}{cc}
\phi_{\mathrm{v} 2}{ }^{0}\left(\mathrm{CK}_{60}\right)>\phi_{\mathrm{v} 2}{ }^{0} & \left(\mathrm{CK}_{80}\right)>\phi_{\mathrm{v} 2}{ }^{0}\left(\mathrm{CK}_{100}\right) \\
\mathrm{S}_{\mathrm{v} 2}\left(\mathrm{CK}_{100}\right)>\mathrm{S}_{\mathrm{v} 2} & \left(\mathrm{CK}_{80}\right)>\mathrm{S}_{\mathrm{v} 2} \quad\left(\mathrm{CK}_{60}\right)
\end{array}
$$

Thus, it is obvious that above CMC, the soap-solvent interaction becomes more pronounced with more percent of polar-solvent methanol while the soap-soap interaction decreases, shown in Table 5. 
Table 5: Values of CMC for $\mathrm{CK}$ soap solutions in $\mathrm{CK}_{100}, \mathrm{CK}_{80}$ and $\mathrm{CK}_{60}$ at $298.15 \mathrm{~K}$.

\begin{tabular}{lccc}
\hline Parameter & $\mathrm{CK}_{100}$ & $\mathrm{CK}_{80}$ & $\mathrm{CK}_{60}$ \\
\hline$\rho$ vs. $c$ & 0.00061 & 0.00057 & 0.00054 \\
$V$ vs. $c$ & 0.00061 & 0.00057 & 0.00054 \\
$\varphi_{v}$ vs. $c$ & 0.00061 & 0.00057 & 0.00054 \\
$\eta$ vs. $c$ & 0.00058 & 0.00053 & 0.00051 \\
$h_{s p}$ vs. $c$ & 0.00058 & 0.00053 & 0.00051 \\
$f_{v}$ vs. $c$ & 0.00058 & 0.00053 & 0.00051 \\
$\left(h_{s p} / \mathrm{c}\right)$ vs. $c$ & 0.00058 & 0.00053 & 0.00051 \\
$(\psi / \sqrt{ } \mathrm{c})$ vs. $\sqrt{ } c$ & 0.00058 & 0.00053 & 0.00051 \\
$\left(\eta / \mathrm{h}_{0}\right)^{2}$ vs. $c^{2}$ & 0.00058 & 0.00053 & 0.00051 \\
$(1 / c)$ vs. $\left\{1 / \log \left(\eta / \mathrm{h}_{0}\right)\right\}$ & 0.00058 & 0.00053 & 0.00051 \\
$\left(C / h_{s p}\right)$ vs. $c$ & 0.00058 & 0.00053 & 0.00051 \\
\hline
\end{tabular}

\subsection{Viscosity}

Flow characterisation of soap solutions in terms of viscometric measurements has been employed as a tool for finding out the CMC of copper soaps in benzene and two compositions of benzene-methanol systems.

The plot of viscosity $\eta$ against concentration $c$ is shown in Figure 5 for CK soap solution in benzene-methanol mixture. The intersection of the two possible straight lines corresponds to the $\mathrm{CMC}$ of the $\mathrm{CK}$ soap. Before $\mathrm{CMC}$, the plot is of the curve nature and after $\mathrm{CMC}$, the viscosity value increases almost linearly. Interestingly, Moulik's equation also fits equally well to our referred systems: ${ }^{32}$

$$
\left(\frac{\eta}{\eta^{0}}\right)^{2}=M+K c^{2}
$$

where $M$ and $K$ are constants. Thus, the values of $M$ and $K$ could be evaluated both below and above CMC and are designated as $M_{1}, M_{2}, K_{1}$ and $K_{2}$, respectively. 


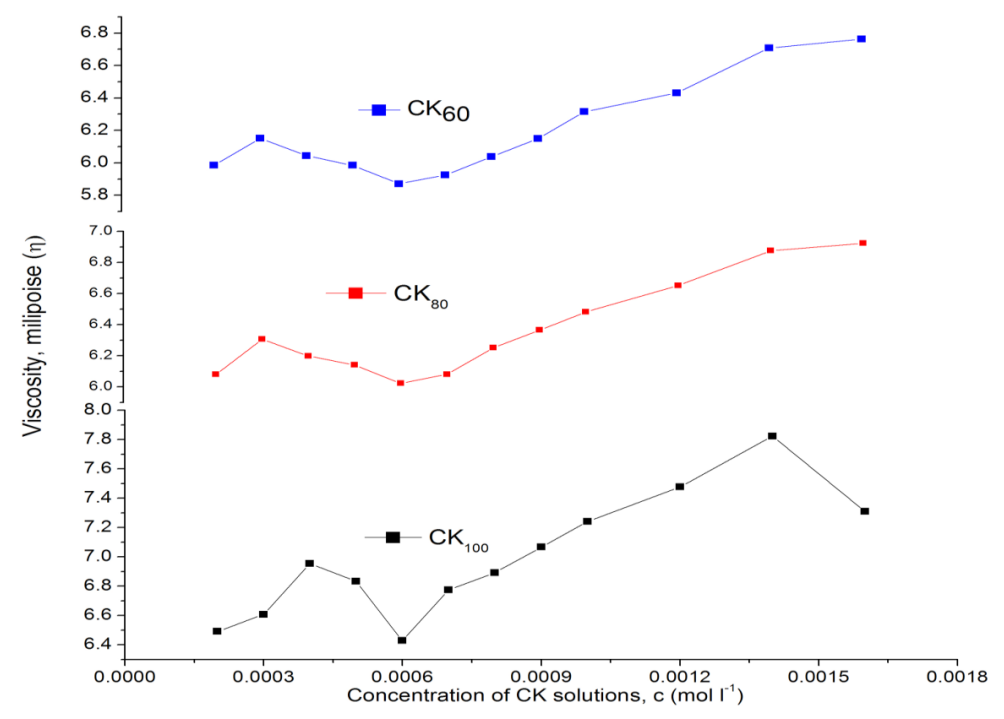

Figure 5: Plot viscosity versus concentration for $\mathrm{CK}$ soap solutions in $\mathrm{CK}_{100}, \mathrm{CK}_{80}$ and $\mathrm{CK}_{60}$ at $298.15 \mathrm{~K}$.

The viscosity data have also been interpreted in the light of Jones-Dole equation. ${ }^{33}$

$$
\frac{\left(\frac{\eta}{\eta_{0}}\right)^{2}-1}{\sqrt{c}}=\mathrm{A}+\mathrm{B} \sqrt{\mathrm{c}}
$$

For convenience, the equation may be expressed as:

$$
\frac{\psi}{\sqrt{c}}=\mathrm{A}+\mathrm{B} \sqrt{\mathrm{c}}
$$

where the coefficient $\mathrm{A}$ and $\mathrm{B}$ refer to the solute-solute and solute-solvent interactions, respectively. The values of $\mathrm{A}$ and $\mathrm{B}$ are evaluated from the plot of $\left(\psi / \sqrt{ }_{c}\right)$ vs. $\sqrt{ } c$, which is characterised by an intersection of two straight lines. Thus, Jones-Dole equations fit well both below and above CMC. The value of CMC obtained is in close agreement with the CMC obtained from $\eta$ vs. $c, \eta_{s p}$ vs. $c$, and $\phi_{v}$ vs. $c$ plots, shown in Figure 6. 


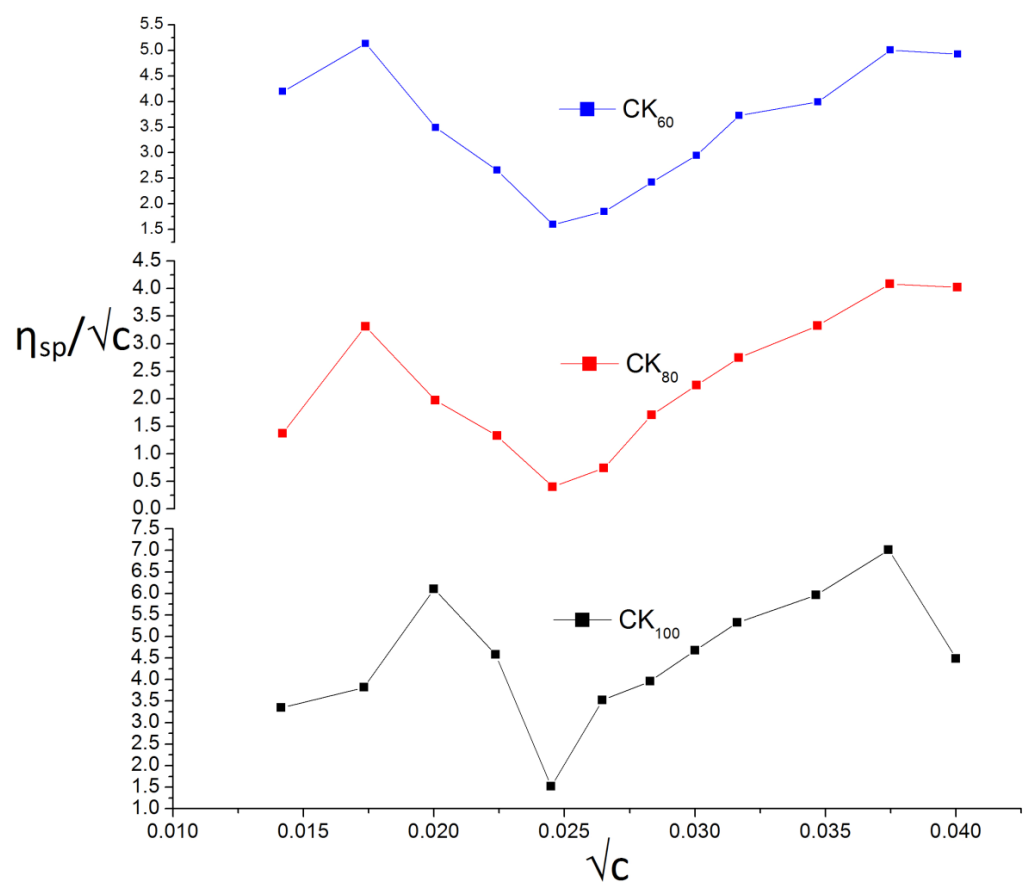

Figure 6: Plot of $\eta \mathrm{sp} / \sqrt{ }_{\mathrm{c}}$ against square root of concentration for $\mathrm{CK}$ soap solutions in $\mathrm{CK}_{100}, \mathrm{CK}_{80}$ and $\mathrm{CK}_{60}$ at $298.15 \mathrm{~K}$ (Jones-Dole equation).

The values of A and B evaluated are recorded in Table 6. Literature survey reveals that positive value of A suggests a strong solute-solute interaction.

Table 6: Computed parameters derived from different equations for CK soap solutions in $\mathrm{CK}_{100}, \mathrm{CK}_{80}$ and $\mathrm{CK}_{60}$ at $298.15 \mathrm{~K}$.

\begin{tabular}{ccccccccc}
\hline \multirow{2}{*}{ Soap } & \multicolumn{4}{c}{ Moulik's equation } & \multicolumn{4}{c}{ Jones-Dole equation } \\
\cline { 2 - 9 } & $\mathrm{M}_{1}$ & $\mathrm{M}_{2}$ & $\mathrm{~K}_{1}$ & $\mathrm{~K}_{2}$ & $\mathrm{~A}_{1}$ & $\mathrm{~A}_{2}$ & $\mathrm{~B}_{1}$ & $\mathrm{~B}_{2}$ \\
\hline $\mathrm{CK}_{100}$ & 1.04 & 0.9107 & -0.9152 & 0.4639 & 26.48 & -12.03 & -1019.00 & 551.90 \\
$\mathrm{CK}_{80}$ & 1.15 & 1.0281 & -0.3660 & 0.1077 & 10.07 & -3.52 & -395.33 & 189.91 \\
$\mathrm{CK}_{60}$ & 1.21 & 1.0740 & -0.3746 & 0.1390 & 13.66 & -2.54 & -492.75 & 186.33 \\
\hline
\end{tabular}

B co-efficient measures the structural modification induced by solute-solvent interaction. Earlier studies show that the increase in concentration of solute in solution contributes positively to the viscosity of B-coefficient. On the other hand, the breaking of the solvent structures by solute causes a decrease in viscosity. 
This contributes negatively to the B-coefficient. Thus, B coefficient is the resultant of these two opposite forces. Therefore, the systems/molecules exhibiting negative B-coefficient have been assumed to exert a structure breaking effect by the solute on the solvent molecules. ${ }^{34}$

It is suggested that solute-solute interaction is greater below $\mathrm{CMC}$ as compared to above $\mathrm{CMC}$ for our referred $\mathrm{CK}_{100}, \mathrm{CK}_{80}$ and $\mathrm{CK}_{60}$ systems as $\mathrm{A}_{1}>\mathrm{A}_{2}$, and $\mathrm{A}_{1}$ is positive while $A_{2}$ is negative for all the systems. Literature survey also reveals that B-coefficient measures the structural modification induced by solute-solvent interaction, and the molecules exhibiting negative B-coefficient have been assumed to exert a structure-breaking effect by the solute on the solvent molecules and it has been observed for our $\mathrm{CK}_{100}, \mathrm{CK}_{80}$ and $\mathrm{CK}_{60}$ systems that the B-coefficient below $C M C$, i.e., $B_{1}$ is negative. This suggests that structure-breaking effect is more below $\mathrm{CMC}$ as $\mathrm{B}_{1}<\mathrm{B}_{2}$. It can be suggested that the structure breaking effect by the solute on the solvent molecules is more prominent below CMC as compared to above $\mathrm{CMC}$, i.e., after the formation of the micelles. ${ }^{35}$

\section{CONCLUSION}

The present research work attempts to prepare surface active organic compounds from natural non-edible oil and to study their solution behaviour, micellar features and various interactions with polar and non-polar solvents to understand the applied part of the solute. The beneficial effects of the synthesised pharmaceuticals and their biological applications may be explored in the further researches. The current topic will not only strengthen relation between industries, private sectors and research laboratories on the focal theme of biology, physics and environment, but also will also play a significant role in forth coming scientific development through the information related to micellar behaviour of surfactants.

\section{ACKNOWLEDGEMENTS}

The authors pay their sincere gratitude to University Grants Commission (UGC), India for financial supports, UGCTRF no F. No:25-223(12)/2006/TRF/ CRO); S. R. K. P. Govt. P. G. College; Government Post Graduate College, Jhalawar; and Government Post Graduate College, Dausa for providing necessary research facilities to accomplish this study. 


\section{REFERENCES}

1. Bhutra, R., Sharma, R. \& Sharma, A.K. (2018). Synthesis, characterization and fungicidal activities of $\mathrm{Cu}$ (II) surfactants derived from groundnut and mustard oils treated at high temperatures. J. Inst. Chem. Ind., 90(3), 66-80.

2. Sharma, R. \& Sharma, A. K. (2017). Natural edible oils: Comparative health aspects of sesame, coconut, mustard (rape seed) and groundnut (peanut): A biomedical approach. Biomed. J. Sci. Tech. Res., 1(5), 1-2, https://doi.org/10.26717/ BJSTR.2017.01.00044.

3. Sharma, S. et al. (2017). Kinetic parameters and photo degradation studies of copper soap derived from soybean oil using $\mathrm{ZnO}$ as a photo catalyst in solid and solution phase. J. Inst. Chem. Ind., 89(4), 119-136.

4. Kannapan, A. N., Thirumam, S. \& Palani, R. (2009). Volumetric and thermodynamic studies of molecular interactions in ternary liquid mixtures at 303, 308 and $313 \mathrm{~K}$. J. Phys. Sci., 20(2), 97-108.

5. Tank, P. et al. (2017). Thermal behaviour and kinetics of copper (II) soaps and complexes derived from mustard and soyabean oil. J. Anal. Pharm. Res., 4(2), 1-5, https://doi.org/10.15406/japlr.2017.04.00102.

6. Khan, S. et al. (2017). Antifungal activities of copper surfactants derived from neem (Azadirecta indica) and karanj (Pongamia pinnata) oils: A pharmaceutical application. Glob. J. Pharm. Sci., 3(4), 1-6.

7. Sharma, A. K. et al. (2018). CMC, solute-solvent interaction of ternary system containing copper soap-2-amino-6-chloro benzothiazole complex, benzene and methanol at 298.15 K. J. Inst. Chem. Ind., 90(4), 121-135.

8. Sharma, S. et al. (2017). Synthesis, characterization, and thermal degradation of $\mathrm{Cu}$ (II) surfactants for sustainable green chemistry. Asian J. Green Chem., 2(2), 129-140, https://doi.org/10.22631/ajgc.2017.95559.1015.

9. Bhutra, R. et al. (2018). Volumetric studies of copper soap derived from treated and untreated oils in benzene at 298.15 K. Bull. Pure Appl. Sci., 37(2), 33-44, https://doi.org/10.5958/2320-320X.2018.00028.6.

10. Sharma, A. K. et al. (2017). Synthesis, spectroscopic and fungicidal studies of $\mathrm{Cu}$ (II) soaps derived from groundnut and sesame oils and their urea complexes. Bull. Pure Appl. Sci., 36(2), 26-37, https://doi.org/10.5958/2320-320X.2017.00004.8.

11. Sumathi, T. \& Varalakshmi, M. (2010). Ultrasonic velocity, density, viscosity measurement of methionine in aqueous electrolytic solution at $303 \mathrm{~K}$. Rasayan $J$. Chem., 3(3), 550-555.

12. Bhutra, R. et al. (2018). Studies of ultrasonic and acoustic parameter of copper (II) surfactants of groundnut and soyabean oils treated at different temperatures. J. Acous. Soc. Ind., 25(1), 42-52.

13. Bhutra, R. et al. (2017). Viscometric and $C M C$ studies of $\mathrm{Cu}(\mathrm{II})$ surfactants derived from untreated and treated groundnut and mustard oils in non-aqueous solvent at 298.15 K. J. Inst. Chem. Ind., 90(2), 29-47. 
14. Singh, S. \& Bahadur, I. (2014). Density and speed of sound of 1-ethyl-3methylimidazolium ethylsulphate with acetic or propionic acid at different temperatures. J. Mol. Liq., 199, 518-523, https://doi.org/10.1016/j. molliq.2014.09.055.

15. Joram, A. et al. (2018). Thermal degradation of complexes derived from copper (II) groundnut soap (Arachis hypogaea) and copper (II) sesame soap (Sesamum indicum). Z. Phys. Chem., 232(4), 459-470, https://doi.org/10.1515/zpch-20171073.

16. Sharma, A. K. et al. (2017). Ultrasonic studies of $\mathrm{Cu}$ (II) soaps derived from mustard and soybean oils. J. Pure Appl. Ultrason., 39(3), 92-99.

17. Babak, M. et al. (2009). Density and viscosity of pyridinium-based ionic liquids and their binary mixtures with water at several temperatures. J. Chem. Therm., 41, 323-329, https://doi.org/10.1016/j.jct.2008.09.001.

18. Khan, S. et al. (2017). Ultrasonic studies of $\mathrm{Cu}$ (II) soap derived from seed oil of Pongamia pinnata (Karanj), in non-aqueous binary and ternary systems at 298.15 K. Mal. J. Chem., 19(2), 99-110.

19. Sharma, A. K. et al. (2017). Acoustic studies of copper soap-urea complexes derived from groundnut and sesame oils. J. Phys. Stud., 21(4), 4601-4606.

20. Tank, P. et al. (2017). A pharmaceutical approach and antifungal activities of copper soaps with their $\mathrm{n}$ and $\mathrm{s}$ donor complexes derived from mustard and soyabean oils. Glob. J. Pharm. Sci., 3(4), 1-4, https://doi.org/10.19080/GJPPS.2017.03.555619.

21. Bhutra, R. et al. (2018). Fungicidal activities of $\mathrm{Cu}$ (II) soaps derived from various oils treated at high temperature for biomedical use. SAJ Biotechnol., 5, 1-6.

22. Sharma, A. K. et al. (2018). Biomedical and antifungal application of $\mathrm{Cu}(\mathrm{II})$ soaps and its urea complexes derived from various oils. Open Acc. J. Trans. Med. Res., 2(2), 40-43, https://doi.org/10.15406/oajtmr.2018.02.00033.

23. Sharma, A. K. et al. (2018). Biomedical and fungicidal application of copper surfactants derived from pure fatty acid. Org. Med. Chem. IJ, 5(5), 1-4, https://doi. org/10.19080/OMCIJ.2018.05.555680.

24. Sharma, A. K. et al. (2018). Antifungal activities and characterization of some new environmentally safe $\mathrm{Cu}$ (II) surfactants substituted 2-amino-6-methyl benzothiazole.OpenPhar.Sci.J.,5,1-11,https://doi.org/10.2174/187484490180501.

25. Pal, A., Chauhan, N. \& Kumar, S. (2010). Interaction of tripeptide with glucose in aqueous solution at various temperatures: A volumetric and ultrasonic study. Thermochim. Acta, 509, 24-32, https:// doi.org/10.1016/j.tca.2010.05.016.

26. Arvind, R., Mahajan, S. \& Mirgane, R. (2013). Volumetric and thermodynamic studies of molecular interactions in binary liquid mixtures of $\mathrm{N}$-alkanes with heptan-2ol at $298.15 \mathrm{~K}$ comparison with Prigoline-Flory theory. Chem. Eng. Commun., 200, 1666-1682, https://doi.org/10.1080/00986445.2012.749785.

27. Tank, P. et al. (2017). Studies of ultrasonic and acoustic parameters of complexes derived from copper (II) surfactant of mustard oil with $\mathrm{N}$ and $\mathrm{S}$ atoms containing ligands in non-aqueous media (benzene) at 303.15 K. J. Acous. Soc. Ind., 44(2), 87-99. 
28. Kondaiah, M. et al. (2011). Ultrasonic velocities, densities, and excess molar volumes of binary mixtures of N,N-dimethyl formamide with methyl acrylate, or ethyl acrylate, or butyl acrylate, or 2-ethyl hexyl acrylate at T=308.15 K. J. Chem. Thermodyn., 43, 1844-1850, https://doi.org/10.1063/1.4990325.

29. Tank, P. et al. (2018). Micellar features and various interactions of copper soap complexes derived from edible mustard oil in benzene at 303.15 K. Curr. Phys. Chem., 8(1), 46-57, https://doi.org/10.2174/1877946808666180102152443.

30. Sharma, A. K. et al. (2018). Ultrasonic studies of $\mathrm{Cu}$ (II) soaps derived from groundnut and sesame oils. Tens. Surf. Det., 55(2), 127-134, https://doi. org/10.3139/113.110544.

31. Masson, D. O. (1929). Solute molecular volumes in relation to solvation and ionization. Philos. Mag., 8, 218-235, https://doi.org/10.1080/14786440808564880.

32. Moulik, S. P. (1968). Proposed viscosity-concentration equation beyond Einstein's region. J. Phys. Chem.,72(13), 4682-4684, https://doi.org/101021/j100859a054.

33. Jones, G. \& Dole, M. (1929). The viscosity of aqueous solutions of strong electrolytes with special reference to Barium chloride. J. Am. Chem. Soc., 51, 2950-2964, https://doi.org/10.1021/ja01385a012.

34. Khan, S. et al. (2018). Acoustic studies and other acoustic parameters of $\mathrm{Cu}(\mathrm{II})$ soap derived from non-edible Neem oil (Azadirecta indica), in non-aqueous media at 298.15 K. Acta. Acust. Unit. Acust., 104, 277-283, https:/doi.org/10.3813/ AAA.919170.

35. Bhutra, R. et al. (2018). Studies of ultrasonic and acoustic parameters of copper (II) surfactant of sesame and soyabean oils treated at different temperatures. J. Pure Appl. Ultrason., 40(2), 46-51. 